\title{
New Hybrid Iterative Schemes for an Infinite Family of Nonexpansive Mappings in Hilbert Spaces
}

\author{
Baohua Guo and Shenghua Wang \\ School of Mathematics and Physics, North China Electric Power University, Baoding 071003, China \\ Correspondence should be addressed to Shenghua Wang, sheng-huawang@hotmail.com \\ Received 20 November 2009; Accepted 4 February 2010 \\ Academic Editor: Anthony To Ming Lau \\ Copyright (C) 2010 B. Guo and S. Wang. This is an open access article distributed under the Creative \\ Commons Attribution License, which permits unrestricted use, distribution, and reproduction in \\ any medium, provided the original work is properly cited. \\ We propose some new iterative schemes for finding common fixed point of an infinite family of \\ nonexpansive mappings in a Hilbert space and prove the strong convergence of the proposed \\ schemes. Our results extend and improve ones of Nakajo and Takahashi (2003).
}

\section{Introduction and Preliminaries}

Let $H$ be a Hilbert space and $C$ a nonempty closed convex subset of $H$. Let $T$ be a nonlinear mapping of $C$ into itself. We use $F(T)$ and $P_{C}$ to denote the set of fixed points of $T$ and the metric projection from $H$ onto $C$, respectively.

Recall that $T$ is said to be nonexpansive if

$$
\|T x-T y\| \leq\|x-y\|
$$

for all $x, y \in C$.

For approximating the fixed point of a nonexpansive mapping in a Hilbert space, Mann [1] in 1953 introduced a famous iterative scheme as follows:

$$
\forall x_{1} \in C, x_{n+1}=\left(1-\alpha_{n}\right) x_{n}+\alpha_{n} T x_{n}, \quad \forall n \geq 1,
$$

where $T$ is a nonexpansive mapping of $C$ into itself and $\left\{\alpha_{n}\right\}$ is a sequence in $(0,1)$. It is well known that $\left\{x_{n}\right\}$ defined in (1.2) converges weakly to a fixed point of $T$. 
Attempts to modify the normal Mann iteration method (1.2) for nonexpansive mappings so that strong convergence is guaranteed have recently been made; see, for example, [2-9].

Nakajo and Takahashi [5] proposed the following modification of Mann iteration method (1.2) for a single nonexpansive mapping Tin a Hilbert space $H$ :

$$
\begin{gathered}
x_{0} \in C \text { chosen arbitrarily, } \\
y_{n}=\alpha_{n} x_{n}+\left(1-\alpha_{n}\right) T x_{n}, \\
C_{n}=\left\{z \in C:\left\|y_{n}-z\right\| \leq\left\|x_{n}-z\right\|\right\}, \\
Q_{n}=\left\{z \in C:\left\langle x_{n}-z, x_{0}-x_{n}\right\rangle \geq 0\right\}, \\
x_{n+1}=P_{C_{n} \cap Q_{n}} x_{0},
\end{gathered}
$$

where $P_{K}$ denotes the metric projection from $H$ onto a closed convex subset $K$ of $H$. They proved that if the sequence $\left\{\alpha_{n}\right\}$ is bounded above from one, then sequence $\left\{x_{n}\right\}$ generated by (1.3) converges strongly to $P_{F}(T) x_{0}$.

In this paper, we introduce some new iterative schemes for infinite family of nonexpansive mappings in a Hilbert space and prove the strong convergence of the algorithms. Our results extend and improve the corresponding one of Nakajo and Takahashi [5].

The following two lemmas will be used for the main results of this paper.

Lemma 1.1. Let $C$ be a closed convex subset of a real Hilbert space $H$ and let $P_{C}$ be the metric projection from $H$ onto $C$ (i.e., for $x \in H, P_{C} x$ is the only point in $C$ such that $\left\|x-P_{C} x\right\|=$ $\inf \{\|x-z\|: z \in C\})$. Given $x \in H$ and $z \in C$, then $z=P_{C} x$ if and only if there holds the following relation:

$$
\langle x-z, y-z\rangle \leq 0, \quad \forall y \in C
$$

Lemma 1.2 (see [10]). Let $H$ be a real Hilbert space. Then the following equation holds:

$$
\|t x+(1-t) y\|^{2}=t\|x\|^{2}+(1-t)\|y\|^{2}-t(1-t)\|x-y\|^{2}, \quad \forall x \in C, \quad \forall t \in[0,1] .
$$

\section{Main Results}

Theorem 2.1. Let $C$ be a nonempty closed convex subset of a Hilbert space $H$. Let $\left\{T_{i}\right\}_{i=1}^{\infty}: C \rightarrow C$ be an infinite family of nonexpansive mappings such that $F=\bigcap_{i=1}^{\infty} F\left(T_{i}\right) \neq \emptyset$. Let $\left\{x_{n}\right\}$ be a sequence generated by the following manner:

$$
\begin{gathered}
x_{1}=x \in C \text { chosen arbitrarily, } \\
y_{i, n}=\left(1-\alpha_{n}\right) x_{n}+\alpha_{n} T_{i} x_{n}, \quad i=1,2, \ldots, \\
C_{n}=\left\{v \in C: \sum_{i=1}^{\infty} \beta_{i}\left\|y_{i, n}-v\right\|^{2} \leq\left\|x_{n}-v\right\|^{2}\right\},
\end{gathered}
$$


Fixed Point Theory and Applications

$$
\begin{gathered}
D_{n}=\bigcap_{j=1}^{n} C_{j}, \\
x_{n+1}=P_{D_{n}} x, \quad n \geq 1,
\end{gathered}
$$

where $\left\{\alpha_{n}\right\}$ is a sequence in $(0,1]$ satisfying $\liminf _{n \rightarrow \infty} \alpha_{n}>0$, and $\left\{\beta_{n}\right\}$ is a sequence in $(0,1]$ satisfying $\sum_{n=1}^{\infty} \beta_{n}=1$. Then $\left\{x_{n}\right\}$ defined by (2.1) converges strongly to $P_{F} x$.

Proof. We first show that $D_{n}$ is closed and convex. By Lemma 1.2, one observes that

$$
\sum_{i=1}^{\infty} \beta_{i}\left\|y_{i, n}-v\right\|^{2} \leq\left\|x_{n}-v\right\|^{2}
$$

is equivalent to

$$
\sum_{i=1}^{\infty} \beta_{i}\left\|y_{i, n}\right\|^{2}-\left\|x_{n}\right\|^{2} \leq 2\left\langle\sum_{i=1}^{\infty} \beta_{i} y_{i, n}-x_{n}, v\right\rangle
$$

for all $n \geq 1$. So, $C_{n}$ is closed and convex for all $n \geq 1$ and hence $D_{n}=\bigcap_{j=1}^{n} C_{j}$ is also closed and convex for all $n \geq 1$. This implies that $P_{D_{n}} x$ is well defined.

Next, we show that $F \subset D_{n}$ for all $n \geq 1$. To end this, we need to prove that $F \subset C_{n}$ for all $n \geq 1$. Indeed, for each $p \in F$, we have

$$
\sum_{i=1}^{\infty} \beta_{i}\left\|y_{i, n}-p\right\|^{2} \leq \sum_{i=1}^{\infty} \beta_{i}\left[\alpha_{n}\left\|x_{n}-p\right\|^{2}+\left(1-\alpha_{n}\right)\left\|T_{i} x_{n}-p\right\|^{2}\right] \leq\left\|x_{n}-p\right\|^{2}
$$

This implies that

$$
p \in C_{n}, \quad \forall n \geq 1 .
$$

Therefore, $F \subset C_{n}$ and $C_{n}$ is nonempty for all $n \geq 1$. On the other hand, from the definition of $D_{n}$, we see that $F \subset D_{n}=\bigcap_{i=1}^{n} C_{j}$ for all $n \geq 1$.

From $x_{n+1}=P_{D_{n}} x$, we have

$$
\left\|x_{n+1}-x\right\| \leq\|v-x\|, \quad \forall v \in D_{n}, n \geq 1 .
$$

Since $z=P_{F} x \in F \subset D_{n}$ for all $n \geq 1$, one has

$$
\left\|x_{n+1}-x\right\| \leq\|z-x\| .
$$


This implies that $\left\{x_{n}\right\}$ is bounded. For each fixed $i \geq 1$, by (2.1) we have (noting that $z=$ $\left.P_{F} x \in F=\bigcap_{i=1}^{\infty} F\left(T_{i}\right)\right)$

$$
\begin{aligned}
\left\|y_{i, n}\right\| & \leq\left\|y_{i, n}-z+z\right\| \leq\left\|y_{i, n}-z\right\|+\|z\| \\
& \leq\left(1-\alpha_{n}\right)\left\|x_{n}-z\right\|+\alpha_{n}\left\|T_{i} x_{n}-z\right\|+\|z\| \\
& \leq\left(1-\alpha_{n}\right)\left\|x_{n}-z\right\|+\alpha_{n}\left\|x_{n}-z\right\|+\|z\| \\
& =\left\|x_{n}-z\right\|+\|z\| \\
& \leq\left\|x_{n}\right\|+2\|z\|
\end{aligned}
$$

for all $n \geq 1$. Since $\left\{x_{n}\right\}$ is bounded, $\left\{y_{i, n}\right\}$ is bounded for each $i \geq 1$.

On the other hand, observing that $D_{n+1} \subset D_{n}$ for all $n \geq 1$, we have

$$
x_{n+2}=P_{D_{n+1}} x \in D_{n+1} \subset D_{n}
$$

for all $n \geq 1$. Since $x_{n+1}=P_{D_{n}} x$, we have

$$
\left\|x_{n+1}-x\right\| \leq\left\|x_{n+2}-x\right\|
$$

for all $n \geq 1$. It follows from (2.7) and (2.10) that the limit of $\left\{x_{n}-x\right\}$ exists.

Since $D_{m} \subset D_{n}$ and $x_{m+1}=P_{D_{m}} x \in D_{m} \subset D_{n}$ for all $m \geq n$ and $x_{n+1}=P_{D_{n}} x$, by Lemma 1.1 one has

$$
\left\langle x_{n+1}-x, x_{m+1}-x_{n+1}\right\rangle \geq 0 .
$$

It follows from (2.11) that

$$
\begin{aligned}
\left\|x_{m+1}-x_{n+1}\right\|^{2} & =\left\|x_{m+1}-x-\left(x_{n+1}-x\right)\right\|^{2} \\
& =\left\|x_{m+1}-x\right\|^{2}+\left\|x_{n+1}-x\right\|^{2}-2\left\langle x_{n+1}-x, x_{m+1}-x\right\rangle \\
& =\left\|x_{m+1}-x\right\|^{2}+\left\|x_{n+1}-x\right\|^{2}-2\left\langle x_{n+1}-x, x_{m+1}-x_{n+1}+x_{n+1}-x\right\rangle \\
& =\left\|x_{m+1}-x\right\|^{2}-\left\|x_{n+1}-x\right\|^{2}-2\left\langle x_{n+1}-x, x_{m+1}-x_{n+1}\right\rangle \\
& \leq\left\|x_{m+1}-x\right\|^{2}-\left\|x_{n+1}-x\right\|^{2}
\end{aligned}
$$

Since the limit of $\left\|x_{n+1}-x\right\|$ exists, we get

$$
\lim _{m, n \rightarrow \infty}\left\|x_{m}-x_{n}\right\|=0
$$

It follows that $\left\{x_{n}\right\}$ is a Cauchy sequence. Since $H$ is a Hilbert space and $C$ is closed and convex, one can assume that

$$
x_{n} \longrightarrow q \in C, \quad \text { as } n \longrightarrow \infty \text {. }
$$


Fixed Point Theory and Applications

By taking $m=n+1$ in (2.12), one arrives that

$$
\lim _{n \rightarrow \infty}\left\|x_{n+2}-x_{n+1}\right\|=0
$$

that is,

$$
\lim _{n \rightarrow \infty}\left\|x_{n+1}-x_{n}\right\|=0
$$

Noticing that $x_{n+1}=P_{D_{n}} x \in D_{n} \subset C_{n}$, we get

$$
\sum_{i=1}^{\infty} \beta_{i}\left\|y_{i, n}-x_{n+1}\right\|^{2} \leq\left\|x_{n}-x_{n+1}\right\|^{2}
$$

This implies that $\lim _{n \rightarrow \infty} \sum_{i=1}^{\infty} \beta_{i}\left\|y_{i, n}-x_{n+1}\right\|^{2}=0$. Since each $\beta_{i} \in(0,1]$, we conclude that

$$
\left\|y_{i, n}-x_{n+1}\right\| \longrightarrow 0, \quad \text { as } n \longrightarrow \infty, i=1,2, \ldots
$$

From (2.16) and (2.18), we get

$$
\left\|y_{i, n}-x_{n}\right\| \leq\left\|y_{i, n}-x_{n+1}\right\|+\left\|x_{n+1}-x_{n}\right\| \longrightarrow 0, \quad \text { as } n \longrightarrow \infty, i=1,2, \ldots
$$

By $\left\|T_{i} x_{n}-x_{n}\right\|=\left(1 / \alpha_{n}\right)\left\|y_{i}-x_{n}\right\|$ and $\liminf _{n \rightarrow \infty} \alpha_{n}>0$, we have

$$
\lim _{n \rightarrow \infty}\left\|T_{i} x_{n}-x_{n}\right\|=0, \quad i=1,2, \ldots
$$

This implies that

$$
q \in F=\bigcap_{i=1}^{\infty} F\left(T_{i}\right)
$$

Finally, we prove that $q=z=P_{F} x$. From $x_{n+1}=P_{D_{n}} x$ and $F \subset D_{n}$, one gets

$$
\left\langle x-x_{n+1}, x_{n+1}-v\right\rangle \geq 0, \quad \forall v \in F .
$$

Taking the limit in (2.22) and noting that $x_{n} \rightarrow q$ as $n \rightarrow \infty$, we get that

$$
\langle x-q, q-v\rangle \geq 0, \quad \forall v \in F
$$

In view of Lemma 1.1, one sees that $q=z=P_{F} x$. This completes the proof. 
Corollary 2.2. Let $C$ be a nonempty closed convex subset of a Hilbert space $H$. Let $T: C \rightarrow C$ be a nonexpansive mapping such that $F(T) \neq \emptyset$. Let $\left\{x_{n}\right\}$ be a sequence generated by the following manner:

$$
\begin{gathered}
x_{1}=x \in C \text { chosen arbitrarily, } \\
y_{n}=\left(1-\alpha_{n}\right) x_{n}+\alpha_{n} T x_{n}, \\
C_{n}=\left\{v \in C:\left\|y_{n}-v\right\| \leq\left\|x_{n}-v\right\|\right\}, \\
D_{n}=\bigcap_{j=1}^{n} C_{j}, \\
x_{n+1}=P_{D_{n}} x, \quad n \geq 1,
\end{gathered}
$$

where $\left\{\alpha_{n}\right\}$ is a sequence in $(0,1]$ satisfying that $\liminf _{n \rightarrow \infty} \alpha_{n}>0$. Then $\left\{x_{n}\right\}$ defined by (2.24) converges strongly to $P_{F} x$.

Proof. Set $T_{n}=T$ for all $n \geq 1, \beta_{1}=1$ and $\beta_{n}=0$ for all $n \geq 2$ in Theorem 2.1. By Theorem 2.1, we obtain the desired result.

Theorem 2.3. Let $C$ be a nonempty closed convex subset of a Hilbert space $H$. Let $\left\{T_{i}\right\}_{i=1}^{\infty}: C \rightarrow C$ be an infinite family of nonexpansive mappings such that $F=\bigcap_{i=1}^{\infty} F\left(T_{i}\right) \neq \emptyset$. Let $\left\{x_{n}\right\}$ be a sequence generated by the following manner:

$$
\begin{gathered}
x_{1}=x \in C \text { chosen arbitrarily, } \\
y_{n}=\alpha_{n} x_{n}+\sum_{i=1}^{n}\left(\alpha_{i-1}-\alpha_{i}\right) T_{i} x_{n}, \\
C_{n}=\left\{v \in C:\left\|y_{n}-v\right\| \leq\left\|x_{n}-v\right\|\right\}, \\
D_{n}=\bigcap_{j=1}^{n} C_{j}, \\
x_{n+1}=P_{D_{n}} x, \quad n \geq 1,
\end{gathered}
$$

where $\left\{\alpha_{n}\right\}_{n=1}^{\infty}$ is a strictly decreasing sequence in $(0,1)$ and set $\alpha_{0}=1$. Then $\left\{x_{n}\right\}$ defined by (2.25) converges strongly to $P_{F} x$.

Proof. Obviously, $C_{n}$ is closed and convex for all $n \geq 1$ and hence $D_{n}=\bigcap_{j=1}^{n} C_{j}$ is also closed and convex for all $n \geq 1$. Next, we prove that $F \subset D_{n}$ for all $n \geq 1$. For any $p \in F$, we have

$$
\begin{aligned}
\left\|y_{n}-p\right\| & =\left\|\alpha_{n}\left(x_{n}-p\right)+\sum_{i=1}^{n}\left(\alpha_{i-1}-\alpha_{i}\right)\left(T_{i} x_{n}-p\right)\right\| \\
& \leq \alpha_{n}\left\|x_{n}-p\right\|+\sum_{i=1}^{n}\left(\alpha_{i-1}-\alpha_{i}\right)\left\|T_{i} x_{n}-p\right\|
\end{aligned}
$$


Fixed Point Theory and Applications

$$
\begin{aligned}
& \leq \alpha_{n}\left\|x_{n}-p\right\|+\sum_{i=1}^{n}\left(\alpha_{i-1}-\alpha_{i}\right)\left\|x_{n}-p\right\| \\
& =\left\|x_{n}-p\right\| .
\end{aligned}
$$

This shows that $p \in C_{n}$ for all $n \geq 1$. Therefore, $p \in D_{n}=\bigcap_{j=1}^{n} C_{j}$ for all $n \geq 1$. It follows that $F \subset D_{n}$ for all $n \geq 1$.

By using the method of Theorem 2.1, we can conclude that $\left\{x_{n}\right\}$ is bounded, $x_{n} \rightarrow p$, $x_{n}-x_{n+1} \rightarrow 0$, and $y_{n}-x_{n+1} \rightarrow 0$ as $n \rightarrow \infty$. This implies that $x_{n}-y_{n} \rightarrow 0$ as $n \rightarrow \infty$.

Next, we show that $p \in F$. To end this, we see a fact. For $p$ and $x_{n}$, we have

$$
\begin{aligned}
\left\|x_{n}-p\right\|^{2} & \geq\left\|T_{i} x_{n}-T_{i} p\right\|^{2}=\left\|T_{i} x_{n}-p\right\|^{2}=\left\|T_{i} x_{n}-x_{n}+\left(x_{n}-p\right)\right\|^{2} \\
& =\left\|T_{i} x_{n}-x_{n}\right\|^{2}+\left\|x_{n}-p\right\|^{2}+2\left\langle T_{i} x_{n}-x_{n}, x_{n}-p\right\rangle
\end{aligned}
$$

and hence

$$
\left\|T_{i} x_{n}-x_{n}\right\|^{2} \leq 2\left\langle x_{n}-T_{i} x_{n}, x_{n}-p\right\rangle
$$

for each $i=1,2, \ldots$.

Observe that $y_{n}+\sum_{i=1}^{n}\left(\alpha_{i-1}-\alpha_{i}\right)\left(x_{n}-T_{i} x_{n}\right)-\left(1-\alpha_{n}\right) x_{n}=\alpha_{n} x_{n}$, that is,

$$
\sum_{i=1}^{n}\left(\alpha_{i-1}-\alpha_{i}\right)\left(x_{n}-T_{i} x_{n}\right)=x_{n}-y_{n}
$$

It follows from (2.28) and (2.29) that

$$
\begin{aligned}
\sum_{i=1}^{n}\left(\alpha_{i-1}-\alpha_{i}\right)\left\|x_{n}-T_{i} x_{n}\right\|^{2} & \leq 2 \sum_{i=1}^{n}\left(\alpha_{i-1}-\alpha_{i}\right)\left\langle x_{n}-T_{i} x_{n}, x_{n}-p\right\rangle \\
& =2\left\langle x_{n}-y_{n}, x_{n}-p\right\rangle \\
& \leq 2\left\|x_{n}-y_{n}\right\|\left\|x_{n}-p\right\| .
\end{aligned}
$$

Since $\left\{\alpha_{n}\right\}$ is strictly decreasing, $x_{n}-y_{n} \rightarrow 0$, and $x_{n} \rightarrow p$ as $n \rightarrow \infty$, we get

$$
x_{n}-T_{i} x_{n} \longrightarrow 0 \quad \text { as } n \longrightarrow \infty
$$

for each $i=1,2, \ldots$. Since each $T_{i}$ is nonexpansive, one has $p \in F\left(T_{i}\right)$ and hence

$$
p \in F=\bigcap_{i=1}^{\infty} F\left(T_{i}\right)
$$

Finally, by using the method of Theorem 2.1, we can conclude that $p=P_{F} x$. This completes the proof. 
Remark 2.4. In this paper, we extend result of Nakajo and Takahashi [5] from a single nonexpansive mapping to an infinite family of nonexpansive mappings.

Remark 2.5. The iterative schemes introduced in this paper are new and of independent interest.

Remark 2.6. It is of interest to extend the algorithm (2.25) to certain Banach spaces.

\section{Acknowledgment}

The work was supported by Youth Foundation of North China Electric Power University.

\section{References}

[1] W. R. Mann, "Mean value methods in iteration," Proceedings of the American Mathematical Society, vol. 4, pp. 506-510, 1953.

[2] H. Iiduka and W. Takahashi, "Strong convergence theorems for nonexpansive mappings and inversestrongly monotone mappings," Nonlinear Analysis: Theory, Methods E Applications, vol. 61, no. 3, pp. 341-350, 2005.

[3] F. Kohsaka and W. Takahashi, "Fixed point theorems for a class of nonlinear mappings related to maximal monotone operators in Banach spaces," Archiv der Mathematik, vol. 91, no. 2, pp. 166-177, 2008.

[4] S.-Y. Matsushita and W. Takahashi, "A strong convergence theorem for relatively nonexpansive mappings in a Banach space," Journal of Approximation Theory, vol. 134, no. 2, pp. 257-266, 2005.

[5] K. Nakajo and W. Takahashi, "Strong convergence theorems for nonexpansive mappings and nonexpansive semigroups," Journal of Mathematical Analysis and Applications, vol. 279, no. 2, pp. 372379, 2003.

[6] N. Shioji and W. Takahashi, "Strong convergence theorems for asymptotically nonexpansive semigroups in Hilbert spaces," Nonlinear Analysis: Theory, Methods E Applications, vol. 34, no. 1, pp. 87-99, 1998.

[7] T. Shimizu and W. Takahashi, "Strong convergence to common fixed points of families of nonexpansive mappings," Journal of Mathematical Analysis and Applications, vol. 211, no. 1, pp. 71-83, 1997.

[8] W. Takahashi and K. Zembayashi, "Strong and weak convergence theorems for equilibrium problems and relatively nonexpansive mappings in Banach spaces," Nonlinear Analysis: Theory, Methods $\mathcal{E}$ Applications, vol. 70, no. 1, pp. 45-57, 2009.

[9] S. Takahashi and W. Takahashi, "Viscosity approximation methods for equilibrium problems and fixed point problems in Hilbert spaces," Journal of Mathematical Analysis and Applications, vol. 331, no. 1, pp. 506-515, 2007.

[10] G. Marino and H.-K. Xu, "Weak and strong convergence theorems for strict pseudo-contractions in Hilbert spaces," Journal of Mathematical Analysis and Applications, vol. 329, no. 1, pp. 336-346, 2007. 